\title{
SENSORIAMENTO REMOTO APLICADO AO COMBATE À INCÊNDIO FLORESTAL NO PARQUE ESTADUAL SERRA DE SANTA BARBARA DE MATO GROSSO
}

\author{
REMOTE SENSING APPLIED TO FIREFIGHTING IN STATE PARK SERRA DE \\ SANTA BARBARA DE MATO GROSSO
}

\author{
Jean Carlos Pinto de Arruda Oliveira ${ }^{1}$ \\ Dércio Santos da Silva ${ }^{2}$ \\ Flávio Gledson Bezerra Vieira ${ }^{3}$
}

\section{Resumo}

O Parque Estadual Serra da Santa Bárbara que está localizado no município de Pontes e Lacerda e Porto Esperidião em Mato Grosso é uma unidade de conservação que sofreu incêndio entre o dia 22 a 31 de julho de 2018, com atuação direta do Corpo de Bombeiros Militar de Mato Grosso - CBMMT que por meio de sensoriamento remoto gerenciou os combates e realizou as dinâmicas de queimas e projeção do incêndio florestal no terreno. O artigo tem como objetivo apresentar como o CBMMT aplicou o sensoriamento remoto no incêndio florestal em Santa Barbara. A pesquisa foi por meio de análise qualitativa e quantitava através de levantamento de imagens disponíveis dos satélites sentinel, landsat e resourcesat, durante o incêndio, bem como, os focos de calor sobreposto diariamente. O sensoriamento remoto aplicado durante o incêndio no parque subsidiou as ações do CBMMT, corroborando com as tomadas de decisões durante o combate.

Palavras-chave: Satélite. Comportamento do fogo. Focos de calor.

\begin{abstract}
The Serra da Santa Bárbara State Park, located in the municipality of Pontes and Lacerda and Porto Esperidião in Mato Grosso, is a conservation unit that suffered fire between July 22 and 31, 2018, with direct action by the Military Fire Brigade of Mato Grosso - CBMMT that by means of remote sensing managed the combats and realized the dynamics of burnings and projection of the forest fire in the field. The article aims to present how the CBMMT applied remote sensing to forest fire in Santa Barbara. The research was through qualitative and quantitative analysis by surveying available images of sentinel satellites, landsat and resourcesat during the fire, as well as, foci of heat superimposed daily. The remote sensing applied during the fire in the park subsidized the actions of the CBMMT, corroborating with the decision making during the combat.
\end{abstract}

Key words: Satellite. Fire behavior. Heat sources

\footnotetext{
${ }^{1}$ Major do Corpo de Bombeiros Militar de Mato Grosso. Bacharel em Gestão de Riscos Coletivos pela UEPA. Pós Graduado em Gestão de Segurança Pública. Pós Graduado em Prevenção, Controle e Combate a Incêndio Florestal.

${ }^{2}$ Tenente Coronel do Corpo de Bombeiros Militar de Mato Grosso. Graduado em Tecnologia de Gestão de Recursos Humanos. Pós Graduado em Gestão Corporativa.

${ }^{3}$ Tenente Coronel do Corpo de Bombeiros Militar de Mato Grosso. Bacharel em gestão de riscos coletivos pela UEPA e Mestre em engenharia pelo ITA-SP
} 


\section{INTRODUÇÃO}

O Parque Estadual Serra da Santa Bárbara que está localizado no município de Pontes e Lacerda e Porto Espiridião em Mato Grosso é uma das Unidades de Conservação Estadual UCE estabelecidas pela antiga Fundação Estadual de Meio Ambiente que atualmente é denominada como Secretaria de Estado de Meio Ambiente - SEMA.

Destarte, Mato Grosso possui 104 Unidades de Conservação - UC, sendo 23 federais, 46 estaduais e 36 municipais, totalizando em uma área 5.406.318,24 ha, equivalente a aproximadamente $6 \%$ do território mato-grossense (SEMA, 2018)

De acordo com a Fundação Eramos de Roterdam (2013) a UC de Serra de Santa Bárbara obteve sua outorga de criação em 23 de agosto de 1999, por força da Lei Estadual $\mathrm{n}^{\circ}$ 7.165, com intuito de estabelecer proteção das amostras dos ecossistemas apresentadas na área de 120.092,11 há. A área está situada na região oeste do Estado há cerca de 450km de Cuiabá, capital do Estado, possui um relevo acidentado com aproximadamente mil metros de altitude.

Esta UCE, apesar da lei de proteção, vem sofrendo diversas degradações ambientais ao longo dos anos desde a sua data de criação, principalmente os danos causados pelo homem, como exemplo, construção de estradas com emprego de explosivos, construção indevida de barragem, pisoteamento de nascentes por bovinos, conforme descrito nos Autos de Infração ${ }^{\circ}$ 47614 e 5.1420 (PROMOTORIA DE JUSTIÇA DE PORTO ESPERIDIÃO, 2015).

Neste contexto, outros crimes ambientais são acometidos nessa área de proteção, sendo recorrentes o uso indevido do fogo que ocasionam os grandes incêndios florestais ${ }^{4}$. Conforme o Instituto Nacional de Pesquisas Espaciais - INPE, nos últimos 3 anos já foram registrados 81 focos de calor ${ }^{5}$, obtendo o maior registro em 2017 que alcançou 38 focos.

Em 2018, durante a temporada incêndio florestal de MT que iniciou dia 15 de julho, a Serra de Santa Bárbara sofreu entre o dia 22 a 31 de julho, um grande incêndio que necessitou da intervenção direta do Corpo de Bombeiros Militar de Estado de Mato Grosso - CBMMT.

Diante de ocorrências como a de Santa Bárbara que além da distância dos núcleos urbanos, possui relevo acidentado que dificulta o monitoramento e fiscalização do Parque. Sendo assim, por intermédio do Termo de Cooperação Técnica n 004/2015 firmado com a SEMA, o CBMMT, instituição estadual legitimada para atender este tipo de emergência, vem aprimorando as atividades de monitoramento dos incêndios florestais e queima controlada ilegal.

\footnotetext{
${ }^{4}$ De acordo com Soares \& Batista (2007, p. 59) incêndio florestal se define em um fogo descontrolado que sua propagação ocorre livremente destruindo o material combustível de uma vegetação.

${ }^{5}$ Focos de Calor: Os focos de calor são oriundos de análises de imagens de dados de diferentes satélites. Quando uma área está sendo queimada e muita energia infravermelha sendo emitida, o sensor do satélite gera um pixel georeferenciado com um conjunto de informações. (INPE, 2018)
} 
Revista Científica do Corpo de Bombeiros Militar de Pernambuco

XVIII Seminário Nacional de Bombeiros - Foz do Iguaçu PR

Vol.04 No11 - Edição Especial XVIII SENABOM - ISSN 2359-4829

Versão on-line disponível em: http://www.revistaflammae.com.

Insta salientar que devido à dimensão territorial do Estado e as inúmeras áreas de proteção, o CBMMT, através do Batalhão de Emergências Ambientais, adotou como principal recurso, o sistema de monitoramento por satélite com intuito de subsidiar as tomadas de decisões para ações de prevenção, controle, combate e responsabilização para com os incêndios florestais.

Desta forma, este artigo tem como objetivo apresentar como o sensoriamento remoto é aplicado nas operações de combate a incêndio florestal no Estado de Mato Grosso.

O presente estudo utilizou como base a UCE Serra de Santa Bárbara e imagens de satélites disponibilizadas pela INPE e a NASA. A metodologia aplicada será a análise qualitativa e quantitativa acompanhada de coleta de dados direta no banco de dado de queimadas do INPE.

Este artigo dispensa hipótese de partida, pois apresenta uma perspectiva indutiva referente às coletas de dados.

\section{SENSORIAMENTO REMOTO APLICADO NOS INCÊNDIOS FLORESTAIS PELO CBMMT}

O CBMMT por intermédio da Portaria $\mathrm{n}^{\circ}$ 001/GABCMDO/2011, de 26 de julho de 2011, ativou o Batalhão de Emergências Ambientais - BEA, unidade especializada para realizar a gestão, a nível estadual, das ações relacionadas aos incêndios florestais. No entanto, somente a partir do ano de 2015 tem aplicado e aprimorado os métodos de monitoramento por satélite auxiliando principalmente nas ações operacionais com objetivo de controlar ou extinguir um incêndio.

Dentre as formas de se realizar um monitoramento de incêndio, devido a extensão do território mato-grossense, o sensoriamento remoto que são "técnicas que utiliza sensores para a captação e registro à distância, sem o contato direto, da energia refletida ou absorvida pela superfície terrestre" (FITZ, 2008, p.109), tem sido empregado com frequência e permitindo a detecção inicial, a análise da propagação 
associado ao comportamento do fogo, bem como, a impacto ocasionado pela cicatriz da queima descontrolada.

Sendo assim, o BEA através da sua seção de operações, com frequência média de 4 vezes ao dia, realiza o monitoramento operacional por satélite. O monitoramento passou ser denominado operacional pois cada detecções de focos de calor são geradas as ocorrências detectadas e em seguida despachadas para as equipes do CBMMT distribuídas pelo Estado.

O monitoramento operacional é realizado por militar do BEA capacitados com o Curso de Geoprocessamento Aplicado aos Incêndios Florestais - CGIF. A capacitação tem como objetivo apresentar as metodologias criadas e adaptadas para o uso do sensoriamento remoto aos incêndios.

A deteç̧ão inicial uma das fases do monitoramento operacional é o momento quando um determinado foco é detectado em uma área de prioridade ambiental como por exemplo as UCE's. Nesta fase, são extraídos os focos de calor de todos os satélites através da plataforma do INPE. O INPE apesar de utilizar desde 2002 o AQUA M-T como satélite de referência para a detecções iniciais são utilizados todos os satélites, pois de acordo com Pereira et al (2012, p. 342), no sua pesquisa referente a validação de focos, durante à análise dos incêndios florestais, $97 \%$ dos focos associados a uma cicatriz se encontra em até $4 \mathrm{~km}$ de distância e $69 \%$ dos focos em até $1 \mathrm{~km}$. Portanto, a precisão no início da detecção não é levada em consideração e sim que em um raio de $4 \mathrm{~km}$ daqueles focos detectado, possivelmente, há um incêndio ou uma queima ilegal.

No entanto, é de suma importância a capacidade de interpretação da resolução espacial ${ }^{6}$ dos sensores de cada satélite após a fase inicial, ou seja, no pós-detecção são analisados os satélites que detectaram o possível incêndio.

As diferentes resoluções espaciais implicam na precisão das coordenadas fornecidas pelos focos de calor extraídos pelo Banco de Dados de Queimadas ${ }^{7}$ da plataforma do INPE. Enquanto os satélites AQUA/TERRA (Polar) possuem resolução

\footnotetext{
${ }^{6}$ Resolução espacial: "Resolução pode ser traduzida como a área real abrangida no terreno por cada pixel correspondente na imagem" (FITZ, 2008, p.116)

${ }^{7}$ Disponível em: https://queimadas.dgi.inpe.br/queimadas/
} 
temporal de $1 \mathrm{~km} \times 1 \mathrm{~km}$, os GOES (Geoestacionários) de $4 \mathrm{~km} \times 4 \mathrm{~km}$ e o S-NPP apresenta resoluções de $750 \mathrm{~m}$ e $375 \mathrm{~m}$.

De acordo com Florenzano (2008) os GOES são aqueles que:

\begin{abstract}
A órbita equatorial, com uma inclinação de 0 (zero) grau, coincide com o plano do equador. [...] o que permite ao satélite completar um giro em torno da Terra em 24 horas, aproximadamente o mesmo período de rotação do planeta. [...] É como se o satélite estivesse "estacionado", o que possibilita observar sempre a mesma área da superfície terrestre.
\end{abstract}

O S-NPP só foi disponibilizado a partir de 2013 pelo BDQueimadas com o sensor Visible Infrared Imager Radiometer Suite (VIIRS). (SANTOS, 2013)

Portanto, ao ser detectado um incêndio, a confirmação ou validação é confirmada por uma guarnição de incêndio florestal - GCIF mais próximo do local do incêndio ou por meio do satélite mais preciso disponível atualmente, neste caso o SNPP de resolução $375 \mathrm{~m}$. Cabe ressaltar que o NPP possui uma frequência de detecção de $12 \mathrm{~h}$, sendo assim, no estado de MT o horário das detecções ocorrem entre $1 \mathrm{~h}$ a $02 \mathrm{~h}$ (manhã) e $13 \mathrm{~h}$ a 14h (tarde), ou seja, se um determinado incêndio iniciou as $10 \mathrm{~h}$ da manhã, horário local, este incêndio dependendo da sua magnitude poderá ser detectado por outros satélites e posteriormente ser confirmado e ter a precisão da localização melhorada após as passagem do S-NPP.

Levando em consideração a distância percorrida pelas equipes de combate, muitas das vezes as confirmações dos incêndios florestais ocorrem por meio de satélite e posteriormente ratificado pelas GCIF's.

Após a fase inicial de detecção por satélites, o incêndio passa ser acompanhado por imagens de satélites com média resolução espacial. Atualmente, estão disponíveis imagens gratuitas de satélites como: Landsat8, Resoucersat 2, Sentinel 2 e CBERS - 4.

Estes satélites têm diferentes resoluções temporais que é o espaço de tempo que o sensor leva para obtenção de cada cena (FITZ, 2008). Essa variabilidade de opções de satélite permite acompanhar a evolução e o comportamento de um incêndio florestal de grande extensão e com longo período de queima. A tabela 1 apresenta algumas resoluções dos satélites mais utilizados pelo BEA, o que permite criar um calendário de disponibilidade de imagem de uma determinada área. 
Revista Científica do Corpo de Bombeiros Militar de Pernambuco

XVIII Seminário Nacional de Bombeiros - Foz do Iguaçu PR

Vol.04 No11 - Edição Especial XVIII SENABOM - ISSN 2359-4829

Versão on-line disponível em: http://www.revistaflammae.com.

Tabela 1 - Resolução espacial e temporal dos sensores utilizados para análise de evolução do incêndio

\begin{tabular}{ccc}
\hline Satélite/Sensor & Resolução espacial & Resolução Temporal \\
\hline Landsat-8/OLI & $15 \mathrm{~m}$ & \\
& $30 \mathrm{~m}$ & 16 dias \\
\hline CBERS - 4/MUX & $100 \mathrm{~m}$ & 26 dias \\
\hline Resourcesat - 2/LISS3 & $20 \mathrm{~m}, 5 \mathrm{~m}(\mathrm{LISS} 3)$ & 24 dias \\
e AWIFS & $56 \mathrm{~m}$ (AWIFS) & \\
\hline Sentinel-2A/B/MSI & $10 \mathrm{~m}$ & 05 dias \\
& $20 \mathrm{~m}$ & \\
\hline
\end{tabular}

Fonte: Adaptado de PENHA (2018)

Diante da tabela 1, a diferença de resolução temporal pode ser evidenciada, como por exemplo, no incêndio florestal atendido pelo BEA na APA das Cabeceiras do Rio Cuiabá que evoluiu para o Parque Estadual Águas do Cuiabá. De acordo com o relatório do Batalhão de Emergências Ambientais (2017) o incêndio iniciou dia 01.09.2017 e foi extinto somente no dia 26.09.2017, ou seja, com uma duração de 26 dias.

Sendo assim, a tabela 2 demonstra quais satélites estavam disponíveis durante o incêndio supracitado ocorrido entre as cidades de Nobres, Rosário Oeste e Santa Rita de Trivelato em Mato Grosso. 
Revista Científica do Corpo de Bombeiros Militar de Pernambuco

XVIII Seminário Nacional de Bombeiros - Foz do Iguaçu PR

Vol.04 No11 - Edição Especial XVIII SENABOM - ISSN 2359-4829

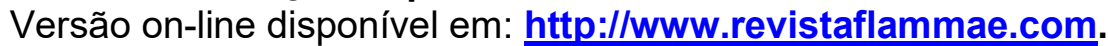

Tabela 2 - Satélites disponíveis para o incêndio na APA das Cabeceiras do Rio Cuiabá e Parque Estadual Águas do Cuiabá, ocorrido em setembro de 2017.

\begin{tabular}{ccc}
\hline Satélite/Sensor & Data da passagem & Resolução \\
\hline Sentinel-2/MSI & 04.09 .2017 & $10 \mathrm{~m}$ \\
Resourcesat - 2/AWIFS & 09.09 .2017 & $56 \mathrm{~m}$ \\
Sentinel-2/MSI & 11.09 .2017 & $10 \mathrm{~m}$ \\
Landsat-8/OLI & 13.09 .2017 & $30 \mathrm{~m}$ \\
Resourcesat - 2/LISS3 & 14.09 .2017 & $23,5 \mathrm{~m}$ \\
CBERS - 4/MUX & 15.09 .2017 & $20 \mathrm{~m}$ \\
Resourcesat - 2/AWIFS & 19.09 .2017 & $56 \mathrm{~m}$ \\
Sentinel-2/MSI & 24.09 .2017 & $10 \mathrm{~m}$ \\
Landsat-8/OLI & 29.09 .2017 & $30 \mathrm{~m}$ \\
\hline
\end{tabular}

Fonte: elaborada pelo autor.

Conforme apresentado na tabela 2, durante os 26 dias foram disponibilizadas 09 imagens do local do incêndio, com sequência de imagens entre o dia 13 a 15.09. Cabe ressaltar que só foram apresentadas as imagens com qualidade suficiente para analisar o impacto da área e o comportamento do incêndio ao logo do período de queima, todas extraídas da plataforma de catálogo de imagens do site do INPE (2018a) e da NASA (2018a).

Nos dias sem disponibilidade de imagens a evolução do incêndio é projetado com a dinâmica de focos de calor do satélite S-NPP com 375 m de resolução, pois apresenta uma boa precisão.

\section{MATERIAIS E MÉTODOS}

Para apresentar a aplicação do sensoriamento remoto durante uma ação de combate a incêndio florestal efetuado pelo CBMMT foi utilizada 04 imagens sendo 02 do satélites Sentinel - 2, 01 do Landsat -8 e 01 do Resourcesat - 2, todas extraídas do catálogo de imagens do INPE (2018b) e da plataforma do NASA (2018b), conforme apresentado na tabela 3 . 
Revista Científica do Corpo de Bombeiros Militar de Pernambuco

XVIII Seminário Nacional de Bombeiros - Foz do Iguaçu PR

Vol.04 No11 - Edição Especial XVIII SENABOM - ISSN 2359-4829

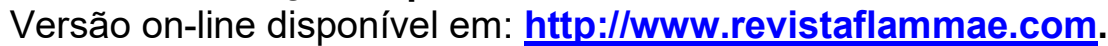

Tabela 3 - Imagens utilizadas durante a operação de combate a incêndio florestal na UCE Serra de Santa Bárbara.

\begin{tabular}{ccc}
\hline Satélite/Sensor & Data da passagem & Órbita/ponto \\
\hline Sentinel-2A/MSI & 24.07 .2018 & $21 \mathrm{LTC}$ \\
ResourceSat - 2/LISS3 & 27.07 .2018 & $317 / 088$ \\
Landsat-8/OLI & 28.07 .2018 & $228 / 071$ \\
Sentinel-2B/MSI & 29.07 .2018 & $20 \mathrm{LRH}$ \\
\hline
\end{tabular}

Fonte: próprio autor

A seleção das imagens levou em consideração a qualidade e o número menor de nuvem apresentada na intersecção da imagem com o polígono da área de estudo, sendo que para o processamento e classificação das cenas em formato geotiff (tiff) foi utilizado o software ARCGIS 10.1.

Em formato de arquivo shapefile (shp), foram coletados, no BDQueimadas disponibilizado pelo INPE, os focos de calor de todos os satélites entre o dia 21 a 31 de julho de 2018, o polígono da área de estudo da Parque Estadual Serra de Santa Bárbara, as bases de terra indigena e curso d'água disponível pela Secretaria de Estado de Planejamento.

Para realizar a dinâmica de detecção do incêndio e apresentação da evolução e as estratégicas de combate e controle subsidiado pelo sensoriamento remoto, foi processada as imagens disponíveis durante o período de queima e sobreposta por focos de calor de forma sequencial em dia a dia com intuito de demonstrar a propagação do incêndio no terreno.

\section{RESULTADO E DISCUSSÃO}

Ao sobrepor os focos de calor do período pesquisado com a base da Parque Estadual de Santa Bárbara foi constatado que a primeira a detecção por satélite foi no dia 22 de julho as $19 \mathrm{~h} 03$. O primeiro satélite a detectar o incêndio foi uma plataforma identificada pelo INPE como GOES - 16, no entanto, por ser um satélite geoestacionário com uma baixa resolução, existe a possibilidade de erro na posição do incêndio. A 
Revista Científica do Corpo de Bombeiros Militar de Pernambuco

XVIII Seminário Nacional de Bombeiros - Foz do Iguaçu PR

Vol.04 No11 - Edição Especial XVIII SENABOM - ISSN 2359-4829

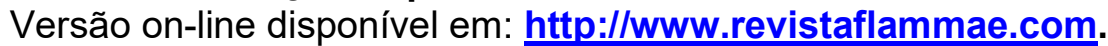

imagem 1 apresenta a posição do primeiro foco detectado por este satélite. Cabe ressaltar, que o horário de detecção apresentado pelos focos de calor conforme disponibilizado pelo INPE é em UTC (Universal Coordinated Time), também chamada de hora média de greenwich (GMT - Greenwich mean time) ou hora zulu, jargão muito utilizado em meio militar. Sendo assim, a Serra está a -4h de fuso horário em relação a hora zulu.

Imagem 1 - a) A posição da $1^{\circ}$ detecção do foco de calor em relação a UCE. b) Imagem ampliada do local detectado pelo Satélite GOES-16 no dia 22.07 as $19 \mathrm{~h} 03$.

(a)
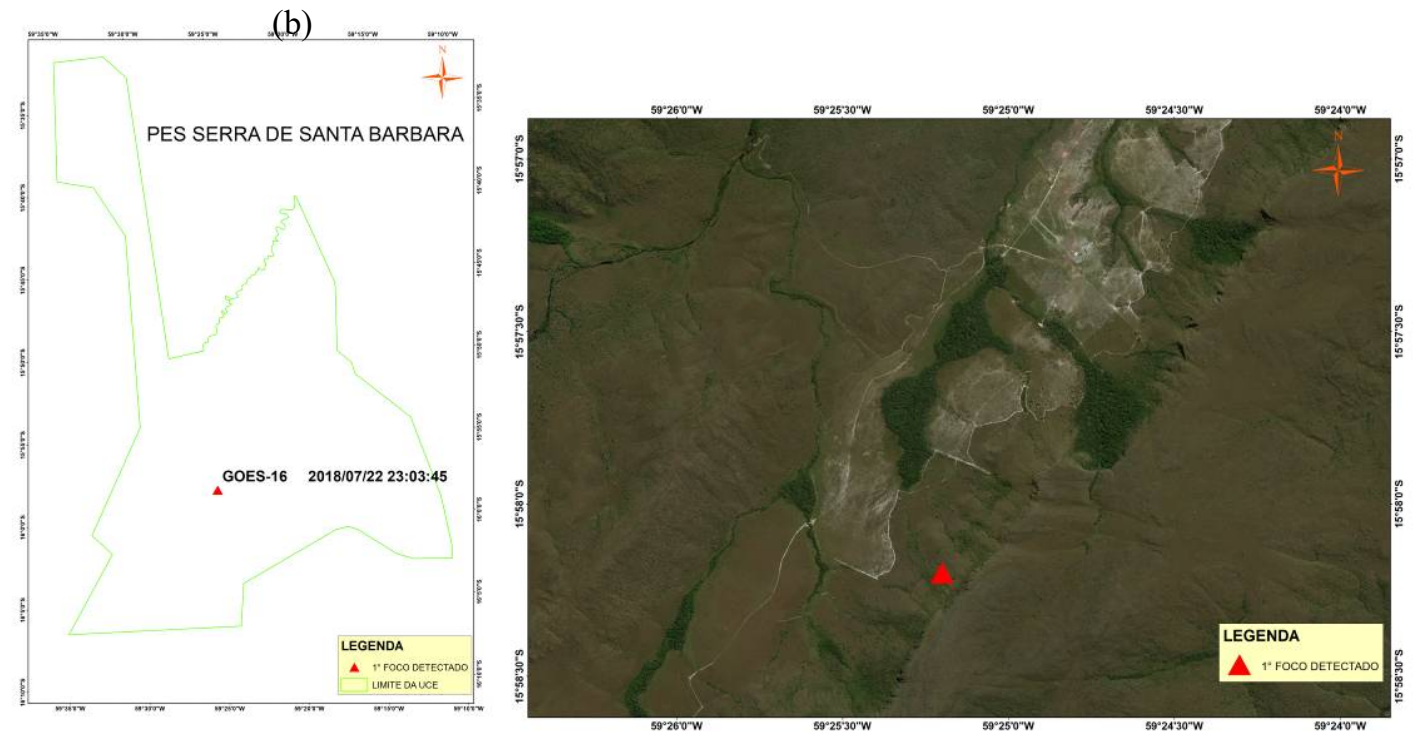

Fonte: elaborada pelo autor

A imagem 1a mostra que o local do incêndio é na região central do Parque, mesmo sendo detectado por um satélite de baixa precisão, ou seja, com um erro de aproximadamente $4 \mathrm{~km}$ do raio do foco, o alerta de incêndio em UCE foi emitido. $\mathrm{Na}$ imagem $1 \mathrm{~b}$ foi utilizada uma basemap $^{8}$ mas desatualizada, pois nesse primeiro momento o mais importante é constatar se há um incêndio, quais as coordenadas para serem utilizadas pelas equipes e um diagnótico preliminar do local inicial.

\footnotetext{
${ }^{8}$ É uma composição de imagens de alta resolução disponível no software Arcgis, no entanto, desatualizadas, mas que auxilia os trabalhos de monitoramento e detecção de uma queimada.
} 
Revista Científica do Corpo de Bombeiros Militar de Pernambuco

XVIII Seminário Nacional de Bombeiros - Foz do Iguaçu PR

Vol.04 No11 - Edição Especial XVIII SENABOM - ISSN 2359-4829

Versão on-line disponível em: http://www.revistaflammae.com.

Por ser um local de difícil acesso, a detecção por satélite é a mais viável, pois o Estado não possui recurso humano suficiente, bem como, outros tipos de plataforma aérea para realizar o monitoramento de forma rápida e econômica.

Ao ser detectado um foco de calor em uma UCE a Seção Operacional do BEA já emite um alerta a equipe mais próxima do local, neste caso seria a Base Descentralizada Bombeiro Militar - BDBM, localizada no município de Vila Bela de Santíssima Trindade, há cerca de $170 \mathrm{~km}$ do local, com uma média de $3 \mathrm{~h} 30$ de viagem até na parte inferior do parque.

Insta ressaltar que para o primeiro monitoramento o BEA utiliza todos satélites para potencializar a chance de detecção, independente da sua precisão. Após a primeira deteç̧ão e a emissão do alerta, o monitoramento aguarda a passagem de um satélite mais preciso como o AQUA/TERRA ou o S-NPP, conforme demonstrado na imagem 2a.

Imagem 2 - a) Apresenta a $1^{\circ}$ detecção do incêndio pelo satélite S-NPP375 no dia 23.07 as 01 h42 (manhã). b) Focos de calor do S-NPP375 no dia 23.07 à tarde.

(a)

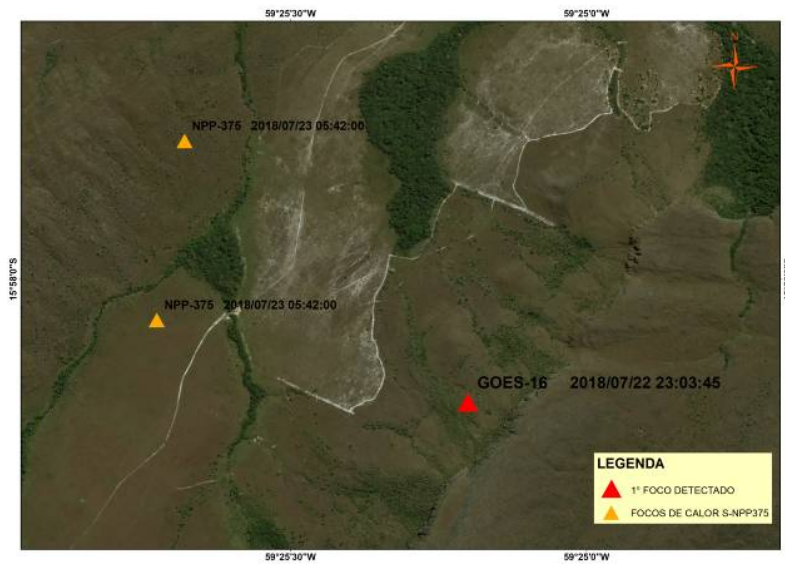

(b)

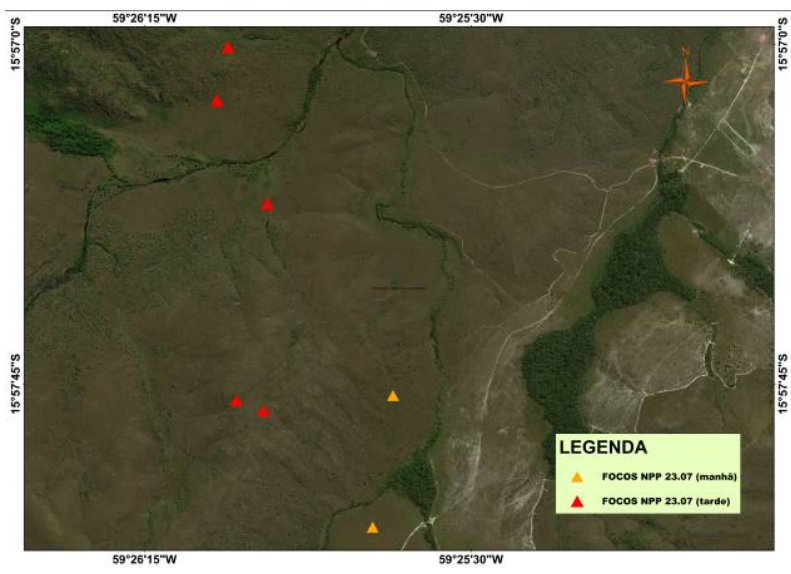

Fonte: elaborado pelo autor

A imagem 2a apresenta a primeira detecção por um satélite considerado mais preciso na deteç̧ão de um foco de calor. Com a detecção do NPP375 às 01 h42 da manhã do dia 23, o incêndio no parque é ratificado e a localização precisa é encaminhada a equipe de $1^{\circ}$ resposta do CBMMT. Através da imagem 2a foi possível constatar que os focos NPP estava aproximadamente há $1 \mathrm{~km}$ do GOES. Considerando 
Revista Científica do Corpo de Bombeiros Militar de Pernambuco

XVIII Seminário Nacional de Bombeiros - Foz do Iguaçu PR

Vol.04 No11 - Edição Especial XVIII SENABOM - ISSN 2359-4829

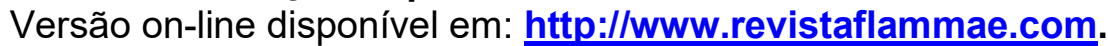

que entre o horário da detecção pelo GOES e NPP há uma diferença de aproximada de $6 \mathrm{~h}$, tempo suficiente para que o incêndio se propague, neste caso foi considerado que o satélite GOES-16 apresentou uma precisão satisfatória, com um raio menor que $1 \mathrm{~km}$.

$\mathrm{A}$ imagem $2 \mathrm{~b}$ demonstra que região de origem do incêndio é uma área degradada, apresentando trilhas e estradas que conforme a base de dados do sistema de cadastro rural da SEMA, a região é composta por fazendas que desenvolvem agropecuária que potencializa a degradação ambiental por meio do uso indevido do fogo para limpeza de pasto.

A propagação dos focos de calor deu-se para setor noroeste do parque, pois o vento que predominava naquele período oscilava entre vento sul e sudeste, conforme preconizado pelo Instituto Nacional de Meteorologia - INMET e evidenciado pelo a distruição dos focos de calor na imagem $2 b$.

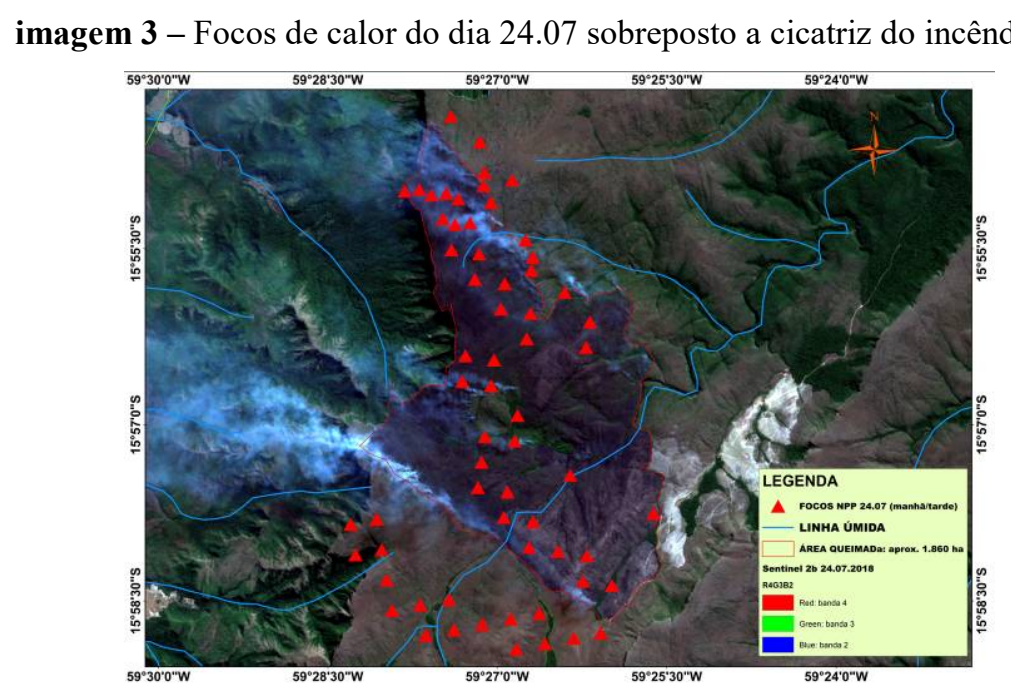

Fonte: elaborada pelo autor.

No dia 24.07 foi a disponibilizada a primeira imagem do satélite Sentinel - 2, sendo assim foram utilizadas as bandas 4, 3 e 2 para a composição RGB, permitindo melhorar a análise de propagação do incêndio no terreno, bem como, confrontar os focos de calor detectado com a área queimada.

A imagem 3 evidencia que provavelmente o incêndio iniciou em uma estrada pois no ponto da $1^{\circ}$ detecção a forma de propagação gerou um incêndio sem cauda ou base, pressupondo que havia uma aceiro ou estrada a retaguarda do local de origem. 
Revista Científica do Corpo de Bombeiros Militar de Pernambuco

XVIII Seminário Nacional de Bombeiros - Foz do Iguaçu PR

Vol.04 N011 - Edição Especial XVIII SENABOM - ISSN 2359-4829

Versão on-line disponível em: http://www.revistaflammae.com.

A imagem consolidou que a propagação se deu para o setor noroeste e que após 40h de incêndio os flancos dividiram - se, formando duas frentes de incêndio, uma para setor noroeste e outro sudoeste. A posição da fumaça corrobora para avaliar a direção do vento no dia auxiliando na avaliação e projeção do incêndio.

Insta salientar que o imageamento pela plataforma sentinel é realizado as 10 h30 da manhã (ENGESAT, 2018), por isso que alguns focos de calor do NPP estão projetados fora da cicatriz do incêndio, pois estes focos são aqueles detectado no período da tarde. Destarte, os focos do NPP 375 da tarde projeta a evolução do incêndio que no dia 24 as $10 \mathrm{~h} 30$ já teria queimado $1.860 \mathrm{ha}$, desta forma os focos que estão fora da cicatriz determinam que a área queimada já seria maior que a vetorizada na imagem 3.

Com a imagem 3 foi possível analisar que o incêndio está entre algumas linhas úmidas que funcionam como aceiros naturais auxiliando no controle do incêndio. Essa informação é extremamente importante e são repassadas para as equipes para que possam definir as estratégias de controle e combate.

Imagem 4 - Distribuição dos focos de calor NPP: a) no dia 25.07. b) no dia 26.07

(a)

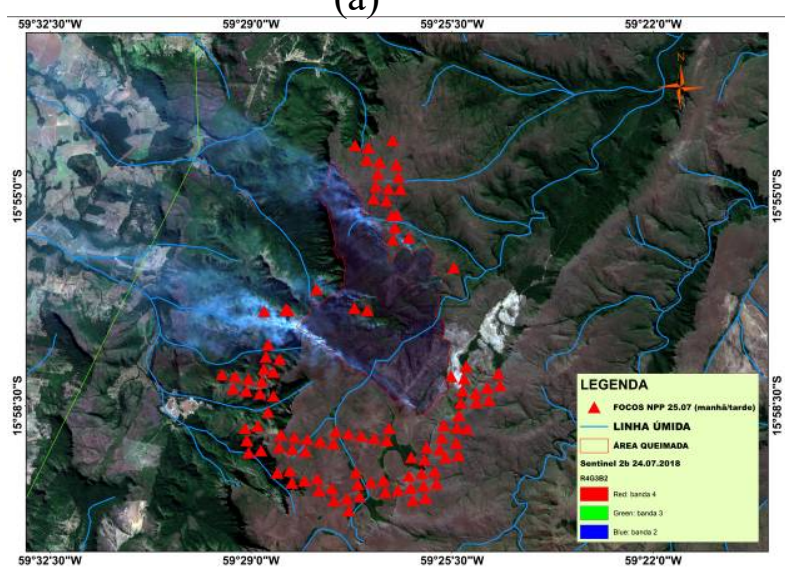

Fonte: elaborada pelo autor (b)

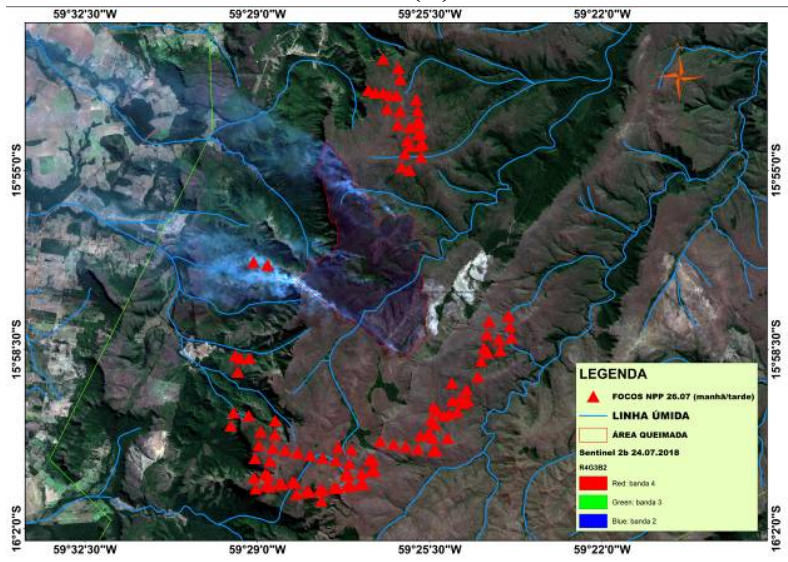

A imagem $4 \mathrm{a}$ dá continuidade na evolução do incêndio no dia 25.07, evidenciando que a frente sul do incêndio, após encontrar um corredor com material combustível com baixa úmida, aumentou sua taxa de propagação, acessando a retaguarda do local de origem do incêndio. De acordo com Soares e Batista (2007b), "o 
Revista Científica do Corpo de Bombeiros Militar de Pernambuco

XVIII Seminário Nacional de Bombeiros - Foz do Iguaçu PR

Vol.04 No11 - Edição Especial XVIII SENABOM - ISSN 2359-4829

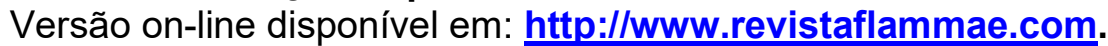

conteúdo de umidade é a mais importante propriedade que controla a inflamabilidade dos combustíveis vivos e mortos".

$\mathrm{Na}$ imagem $4 \mathrm{~b}$, demonstra que no dia 26 a frente sul está se propagando no sentido sudeste, ou seja, contra ao vento, no aspecto tático de combate, apesar da proporção da linha do incêndio, a situação se torna favorável, haja vista, o fogo se propagar contra o vento e se aproximar a uma barreira úmida proporcionada por materiais combustível com alta umidade e possíveis nascentes evidenciada pela coloração verde na imagem.

Imagem 5 - a) distribuição de focos de calor no dia 27.07 com a cicatriz de queimada do satélite Resourcesat 2. b) distribuição de focos de calor no dia 28.07 com a cicatriz de queimada do satélite Landsat8.

(a)

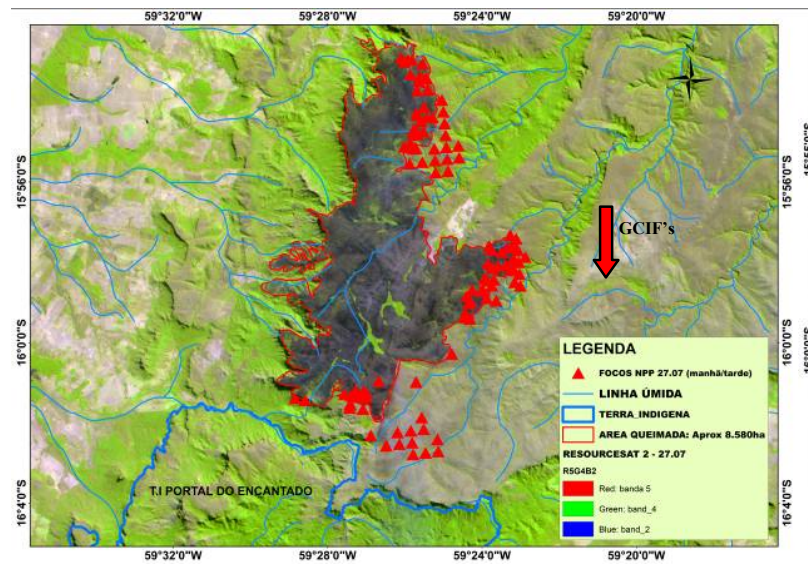

(b)

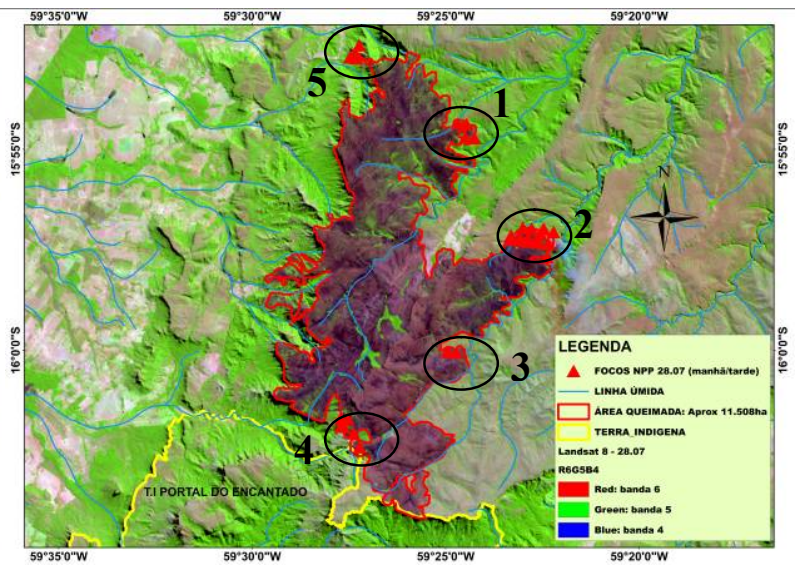

Fonte: elaborada pelo autor.

A imagem 5a apresenta a distribuição dos focos de calor no dia 27.07, bem como, a cicatriz de queimada nesta data. Em 5 dias de incêndio, aproximadamente 8.580ha do parque foram impactados pelo incêndio. Devido a complexidade do terreno, somente no dia 27 a GCIF do BEA conseguiu acessar a parte superior da serra, local mais próximo da frente fogo no setor leste do incêndio, conforme demonstra na imagem 5a. No entanto, fica evidente que o focos de calor que avança no setor sul estão localizados numa área com material combustível de fácil combustão e propagação, desta forma ameaçando a Terra Indígena Portal do Encantado. 
Revista Científica do Corpo de Bombeiros Militar de Pernambuco

XVIII Seminário Nacional de Bombeiros - Foz do Iguaçu PR

Vol.04 N011 - Edição Especial XVIII SENABOM - ISSN 2359-4829

Versão on-line disponível em: http://www.revistaflammae.com.

Pela imagem 5 b do dia 28 , há 5 pontos quentes detectados pelos focos de calor sendo que os pontos 1, 2 e 3 apresentavam baixo potencial de propagação pois estavam cercados por barreiras úmidas, fato confirmado após o sobrevoo de avaliação do incêndio realizado pelo Centro Integrado de Operações Aéreas - CIOPAER. Consequentemente, foi orientado que a equipe abandonasse a posição e concentrasse os esforços nos pontos 4 e 5 , sendo que o ponto 4 ainda ameaçava a terra indígena. Cabe ressaltar que no dia 28 , aproximadamente 11.500 ha já tinha sido impactado.

Imagem 6 - a) focos de calor e cicatriz de queimada no dia 29.07. b) todos os focos de calor gerado entre o dia 22 e 31.07 de 2018.

(a)



(b)

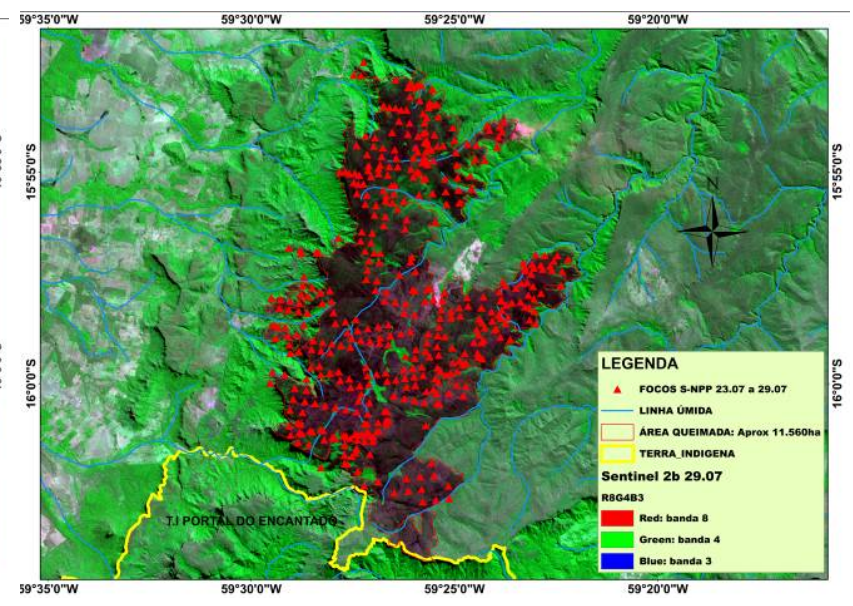

Fonte: elaborada pelo autor

Por meio da imagem 6a ficou constatado que no período da manhã no dia 29 havia somente dois pontos, sendo um no setor nordeste que estava confinado entre duas nascentes e outro no setor sudeste. O Grupo de Aviação Bombeiro Militar - GAVBM foi acionado para auxiliar as equipes terrestres através do combate aérea.

A ultima detecção de focos de calor foi no dia 29.07 as $10 \mathrm{~h} 10$, no entanto, o incêndio só foi considerado extinto no dia 31.07. A não detecção de focos de calor no dia 30 e 31 não ocorreu pois os pontos que ainda estavam ativos não atingiam os parâmetros mínimos para serem detectados, haja vista, serem linha de incêndio isoladas e de baixo potencial de risco. 
O incêndio no parque com duração de 10 dias gerou 431 focos de calor pelo satélite S-NPP375 todos sobrepostos a cicatriz do incêndio com uma média de 37 focos para cada $1000 \mathrm{ha}$.

O incêndio alcançou seu ápice nos dias 25, 26 e 27.07, com 106, 113 e 104 focos respectivamente. Desta forma $75 \%$ dos focos de calor gerado em 3 dias impactaram aproximadamente $7.200 \mathrm{ha}$ do parque, considerado assim a fase mais turbulenta do incêndio, que corrobora com a importância do ataque inicial tão logo seja detectado o incêndio. Não foi necessário gerar imagem após a data de extinção, haja vista a cicatriz de queima não ter evoluido após a imagem do satélite Sentinel-2b disponibilizada no dia 29.

\section{CONCLUSÕES}

O Sensoriamento remoto em consonância com o conhecimento técnico de combate a incêndio florestal demonstrou ser uma ferramenta eficiente para subsidiar o planejamento tático de combate. Desta forma, o analista de imagem deverá constantemente avaliar a área desde a primeira deteç̧ão de focos de calor, elencando fatores que influenciam no comportamento e a propagação do fogo como tipo de material combustível e sua umidade, condições meteorológicas e topografia.

$\mathrm{O}$ artigo salientou a importância do ataque inicial logo após a detecção do incêndio evitando que o mesmo alcance proporção de difícil controle, ocasionando impacto direto nos recursos logísticos empregado para a sua extinção, tornando uma operação de alto custo para o Estado. Cabe ressaltar que devido a distância do incêndio com a equipe mais próxima, o terreno desconhecido pelas GCIF's, bem como, a falta da logística de transporte aéreo imprescindível para esse tipo de incêndio retardaram consideravelmente o inicio do combate.

O satélite S-NPP375 apresentou precisão nas detecções demonstrando a confiabilidade para o uso operacional, auxiliando na análise de projeção do incêndio nos dias que não há imagem disponível. Além de propiciar informações complementares 


\section{Revista FLAMMAE}

Revista Científica do Corpo de Bombeiros Militar de Pernambuco

XVIII Seminário Nacional de Bombeiros - Foz do Iguaçu PR

Vol.04 No11 - Edição Especial XVIII SENABOM - ISSN 2359-4829

Versão on-line disponível em: http://www.revistaflammae.com.

para subsidiar a perícia de incêndio florestal em consonância com outros satélites menos preciso.

Portanto, a variabilidade de imagens gratuitas disponíveis pelos satélites Sentinel - 2, Resourcesat - 2, Landsat- 8 , entre outros, facilitou a aplicação do sensoriamento remoto dia a dia durante a operação de combate no UCE Serra de Ricardo Franco. Sendo que a plataforma Sentinel - 2 foi a mais utilizada por apresentar uma resolução espacial de 10m com uma disponibilidade de imagem em 5 em 5 dias.

\section{REFERÊNCIAS}

BATISTELLA, Alexandre Milaré. Unidades de Conservação Estaduais. Disponível em: $<$ http://www.sema.mt.gov.br/index.php?option=com_content\&view=article\&id=155\&It emid=288 Acesso em: 16, ago, 2018, 09h30.

BATALHÃO DE EMERGÊNCIAS AMBIENTAIS. Relatório do incêndio no Parque Estadual Serra de Santa Barbara. Cuiabá, 2018. 11p.

CORPO DE BOMBEIROS MILITAR DE MATO GROSSO. Portaria ${ }^{\circ}$ 001/GAB/2011, de 26 de julho de 2011. Boletim Geral Eletrônico - BGE n ${ }^{\circ} 524$ de 26 de julho de 2011. p. 12.

ENGESAT. Sentinel Disponível em: $<$ http://www.engesat.com.br/sentinel-2/. Acesso em: 19, ago, 2018, $17 \mathrm{~h} 15$.

FITZ, P. R. Cartografia básica. São Paulo: Oficina de Textos, 2008.

FLORENZANO, Teresa Gallotti. Os satélites e suas aplicações. São José dos Campos: SindCT, 2008.

FUNDAÇÃO ERASMO DE ROTERDAM. Plano de Manejo: Parque Estadual de Santa Barbara. Curitiba, 2003

INSTITUTO NACIONAL DE METEOROLOGIA (INMET). Disponível em: $<$ http://www.inmet.gov.br/portal/index.php? $\mathrm{r}=$ clima/normaisClimatologicas. Acesso em: 20, ago, 2018, $12 \mathrm{~h} 10$.

INSTITUTO NACIONAL DE PESQUISAS ESPACIAIS (INPE). BDQUEIMADAS Banco de Dados Queimadas. Disponível em:

$<\mathrm{http}: / /$ www.dpi.inpe.br/proarco/bdqueimadas. Acesso em: 17, ago, 2018, $15 \mathrm{~h} 15$. 
Revista Científica do Corpo de Bombeiros Militar de Pernambuco XVIII Seminário Nacional de Bombeiros - Foz do Iguaçu PR

Vol.04 N011 - Edição Especial XVIII SENABOM - ISSN 2359-4829

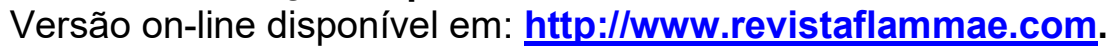

INSTITUTO NACIONAL DE PESQUISAS ESPACIAIS (INPE). Divisao Geral de Imagens - DGI. Disponível em: $<$ http://www.dgi.inpe.br/catalogo. Acesso em: 18, ago, 2018, 16h30a.

INSTITUTO NACIONAL DE PESQUISAS ESPACIAIS (INPE). Divisao Geral de Imagens - DGI. Disponível em: $<$ http://www.dgi.inpe.br/catalogo. Acesso em: 20, ago, 2018, 11h10b.

MATO GROSSO. Ministério Público. Promotoria de Justica de Porto Esperidião.

Notificação Recomendatório n.03/2015 de 05 de agosto de 2015.

PENHA, Thales Vaz. Detecção de áreas queimadas na amazônia utilizando imagens de média resolução espacial, técnicas de geobia e mineração de dados. 139 f. Dissertação (Mestrado em Sensoriamento Remoto) - INPE, São José dos Campos, SP, 2018

PEREIRA, Allan Arantes. Et all. Validação de focos de calor utilizados no monitoramento orbital de queimadas por meio de imagens TM. Cerne, Lavras, vol. 18, núm. 2, p.335-343, 2012.

\section{SECRETARIA DE ESTADO DE MEIO AMBIENTE. Termo de Cooperação Ténica $n^{\circ}$ 004/2015. Cuiabá, MT. 2015.}

SOARES, R. B. et al. Aplicação de técnica de fusão em imagens Landsat8/OLI. In: Simpósio Brasileiro de Sensoriamento Remoto - SBSR, n 17, 2015, Paraíba. Anais..., Paraíba: INPE, 2015. p. 4836-4843

SOARES, Ronaldo Viana. BATISTA, Antônio Carlos. Incêndios Florestais: Controle, Efeitos e Uso do Fogo. Curitiba, 2007.

United States Geological Survey (USGS). Earth Explorer. Disponível em: $<\mathrm{https}$ ://earthexplorer.usgs.gov/ > Acesso em: 18, ago, 2018, 16h35a.

United States Geological Survey (USGS). Earth Explorer. Disponível em: $<$ https://earthexplorer.usgs.gov/ > Acesso em: 20, ago, 2018, 11h20b. 